\title{
APPLICATIONS OF MULTIVARIATE ANALYSIS TO THE FITNESS ASSESSMENT OF SOCCER PLAYERS
}

\author{
T. REILLY and V. THOMAS
}

\section{Liverpool Polytechnic}

Fitness studies have usually been limited to a few variables, for example, aerobic power by oxygen uptake (Saltin and Åstrand, 1967) and anaerobic power (Margaria et al, 1966). More recently, fibre typing from muscle biopsy samples has been employed. (Gollnick et al, 1972). In broader perspective fitness is multifaceted and fitness requirements are sports specific so that univariate analysis has limited prognostic utility. We have conducted fitness tests employing inter-disciplinary and multivariate methods of data analysis.

Data were obtained on all professional players in an English League Football club $(n=31)$ at the beginning of the competitive season, and included anthropometric (linear, circumferential, body composition), muscular strength and power (determined using dynamometry, tensiometry and performance tests), psychomotor (RT), circulatory (resting, submaximal and maximal responses) and personality parameters (Cattell et al, 1970). Standardised test procedures were followed (Clarke, 1967; Weiner and Louire, 1969). These constituted a 65 x 31 observation matrix.

The Principal Components Analysis method was used according to Kaiser (1958), and identification of components was attempted from the test-item eigenvalues. Twelve components were extracted which accounted for 81 per cent of the total variance. Individual scores on the first six components were plotted two at a time in various combinations to investigate clustering according to playing position, proficiency level, and match-play behaviour measured by the method of Reilly and Thomas (1976). Correlational analysis was performed between two components and (a) total distance covered per game and (b) time to cover four laps of a $200 \mathrm{~m}$ running track.

The difference between the League Team $(n=16)$ and the Reserve Team $(n=15)$ was studied using functional discriminatory analysis. In the first instance separate analyses were performed for anthropometry, strength and muscular power, circulatory and personality factors. In the second instance discrimination was on the basis of scores on the first six components extracted, considered as a whole.

Three psychological components were among the twelve extracted in preliminary solution, which were interpreted and named tentatively. The first two components, together accounted for 33 percent of the total variance and were related to body size and density respectively. The next four components, explaining a further 26 per cent of the total variance, were named "resting cardiac efficiency", "stamina", "strength" and "quadriceps strength". The psychological components appeared related to Eysenck's categories of stability and extraversion. The remaining components were named "stress tolerance", "power" and "lung power".

Clustering of individuals according to positional roles showed the most homogeneous group was the centrebacks, followed by goalkeepers and mid-fielders. The greatest heterogeneity was found in strikers, though strikers with similar tactical roles clustered together. The lack of generality to all playing roles was probably attributable to the ability of the younger players to exchange positions to meet needs as tactical contingencies arise. Establishment of clear cut distinctions between all conventional playing positions would require a larger sample of subjects well established in defined roles.

Irrespective of playing position, players who did not achieve First Team selection during the season tended to group together. When behavioural data from competition was juxtaposed on the component scores the poorer tacklers and injury suspect players tended to congregate. Component 3 correlated significantly with match-play work rate $(R=0.50 ; P<.01)$ and with $800 \mathrm{~m}$ run time $(R=0.45 ; P<.01)$. Component 4 correlated significantly with match-play work rate $(R=0.56 ; P<.01)$ and with $800 \mathrm{~m}$ run time $(R=0.53 ; P<.01)$. Higher correlation coefficients could be expected with increased duration of running.

Significant group separation was demonstrated by analysis of the strength and muscular power data $(P<$ $.01)$. Non-significant results were obtained for the anthropometric, circulatory and personality sets $(P>.05)$. Group separation was highlighted when the six principal component scores were used $(P>.01)$. In this analysis significant univariate $F$ ratios were found on two of the components $(P>.05)$, while the goalkeeper was identified as misclassified in the League Team. Of two misclassifications in the Reserve Team, one established himself as a regular League Team player during the season. Misclassified players in the other analyses did in general change their group membership during the season in the direction predicted. These results suggest that this type of functional analysis can be a very useful predictive 
procedure. Apart from possible uses to assist selection, this technique could help to pinpoint areas of specific individual weakness which appropriate training could remedy.

The results encourage further use of multivariate analysis in data reduction in soccer players particularly to clarify interactions between positional roles and level of playing proficiency. Wasteful items in the test battery could now be eliminated and further research could investigate the stability of the components extracted here throughout a season.

\section{REFERENCES}

Cattell, R. B., Ebor, H. W., and Tatsuoka, M. M. 1970. Handbook for the sixteen personality factor questionnaire (16PF). Institute for Personality and Ability Testing, Illinois.

Clarke, H. H. 1967. Application of measurement to health and physical education. Prentice-Hall New Jersey.

Gollnick, P. D., Armstrong, R. B., Saubert, C. W., Piehl, K., and Saltin, B., 1972. Enzyme activity and fiber composition in skeletal muscle of trained and untrained men. J.Appl.Physiol., 23, 312-319.

Kaiser, H. F., 1958. The varimax criterion for analytic rotation in factor analysis. Psychometrica, 23, 187-200.

Margaria, R., Aghemo, P. and Rovelli, P. 1966. Measurement of power (anaerobic) in man. J.Appl.Physiol., 21, $1661-1664$.

Reilly, T. and Thomas, V. 1976. A motion analysis of work-rate in different positional roles in professional football match-play. J.Hum.Movem't Studies, 2, 87-97.

Saltin, B. and Åstrand, P.O., 1967. Maximal oxygen uptake in athletes. J.Appl.Physiol. 23, 353-358.

Weiner, J. S. and Louire, J. A. 1969. Human biology: a guide to field methods. Blackwell, Oxford. 